\section{Kongress in Istanbul}

S. Weiss

Es ist schön, dass sich Weiterbildung oft mit kulturellen Erlebnissen kombinieren lässt. Eine Stadt wie Istanbul ist prädestiniert dazu.

Am Flughafen der grossen Stadt kam es bei unserer Ankunft spät nach Mitternacht zu einer geheimnisvollen Begegnung mit heimkehrenden Pilgern. Das Grüpplein stiller, schattenhafter, übermüdeter Hadjis in ihren hellen Gewändern, die meisten eine Zehn- oder sogar Zwanzig-Liter-Plastikflasche mit geweihtem Wasser aus Mekka in der Hand, wankte durch die wenigen spät angekommenen übrigen Fluggäste, verschwand ebenso still, wie es gekommen war und führte uns vor Augen, dass wir an einem Treffpunkt verschiedener Kulturen angekommen waren.

Korrespondenz:

Dr. med. Severin Weiss

Effingerstrasse 14 a

CH-3011 Bern
Die Stadt wurde im 6. Jahrhundert vor Christus durch griechische Siedler aus Megara gegründet und Byzantion genannt, kam dann in römische Herrschaft unter dem Namen Konstantinopel. Vom 6. bis 12. Jahrhundert wurde Byzanz Sitz der oströmischen Kaiser. Um 1350 war die Bevölkerung der Stadt von 500000 auf knapp 50000 Einwohner geschrumpft. 1453 erfolgte die osmanische Eroberung und der neue Name Istanbul mit einer Blütezeit des Islams und des osmanischen Reiches, die bis zum ersten Weltkrieg dauerte.

Diese grosse Geschichte wird während der Fahrt vom Flughafen zur Stadt entlang dem Marmarameer und den gewaltigen Stadtmauern, die immer wieder aus der Dunkelheit auftauchen, zum ersten Mal lebendig. Es folgt der überwältigende Anblick der riesigen, auch in der Nacht sichtbaren Moscheen. Am nächsten Morgen gelang es unserem Touristenführer, uns in ausgezeichnetem Deutsch einen kurzen Einblick in die Geschichte und das heutige pulsierende Leben der mit zwölf Millionen Einwohnern grössten Stadt Europas zu geben.

Der Nachmittag und der folgende Morgen waren ausgefüllt mit der Teilnahme am Kongress. Am Abend verlief die Fahrt zum Besitkaspalast sehr anregend, sass ich doch neben einem Kollegen aus Saudi-Arabien, der mir von den Schwierigkeiten seines Landes berichtete. Pro Jahr nehmen fast zwei Millionen Pilger aus der ganzen Welt teil an einer Pilgerfahrt nach Mekka und Medina, den heiligsten Stätten des Islam.

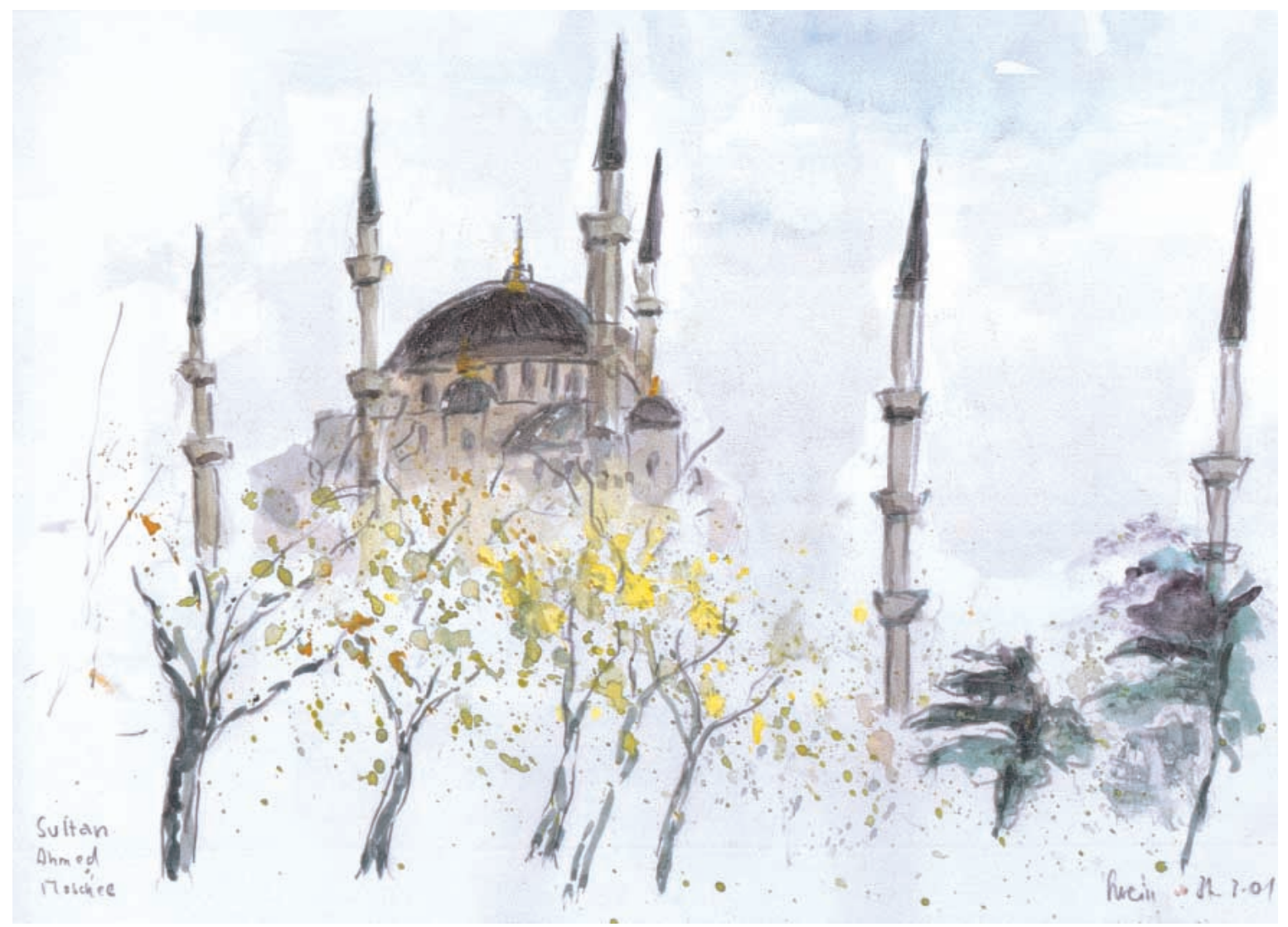

Sultan Ahmed Moschee. 


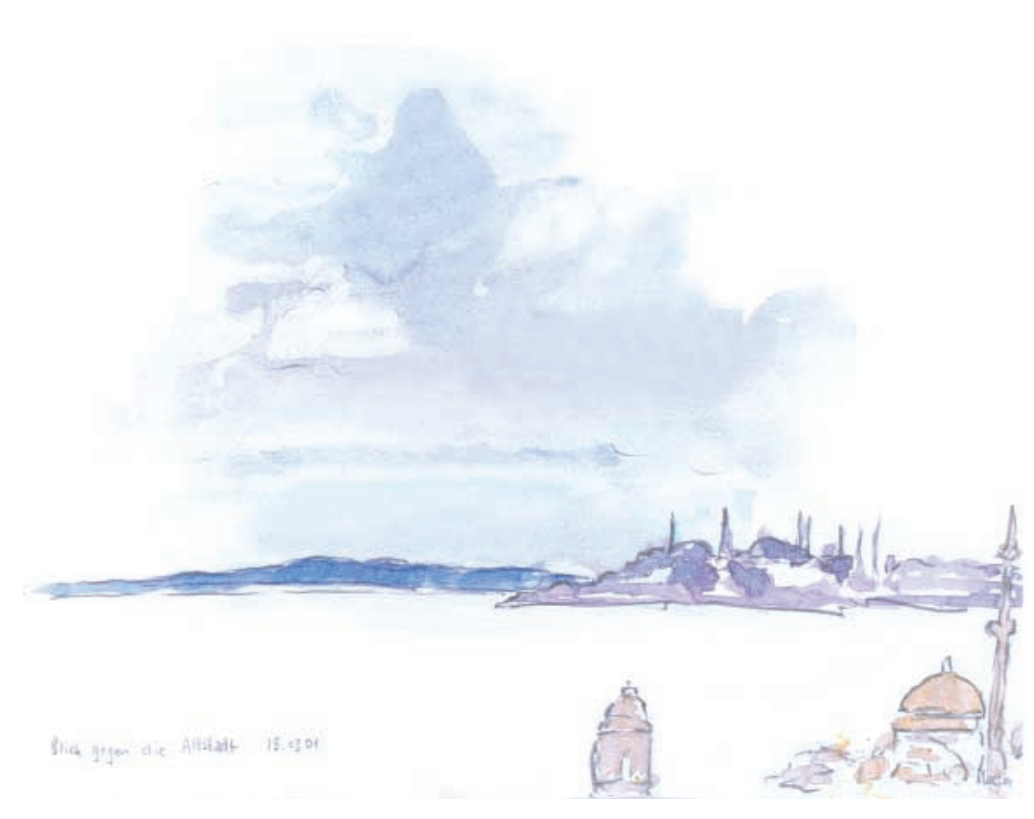

Blick gegen die Altstadt.

Durch diese mehrere Tage dauernde Hadj kommt es jedes Jahr während einiger Wochen zu einer enormen ökologischen Belastung der Infrastruktur, so dass Saudi-Arabien in nächster Zeit die Anzahl der Pilger limitieren muss.

Nach dem Kongress konnte ich während einiger Tage noch in aller Musse Istanbul besichtigen. Erstaunlicherweise klappt der Verkehr dieser Weltstadt mit einer verschwindend kleinen Zahl öffentlicher Verkehrsmittel. Blau-orange Busse, gelbe Taxis, die sehr billig sind, Sammeltaxis (Dolmus) und viele Stadtdampfer, die den Vaporetti in Venedig gleichen, sowie einige wenige Tramlinien sind die wichtigsten öffentlichen Transportmittel. Eine Fahrt mit einem gelben Taxi und den tollkühnen Fahrern, die in den endlosen Verkehrskolonnen immer wieder eine kleine Lücke ausmachen und sich hineinschlängeln, kann nur Leuten mit guten Nerven empfohlen werden. Um so gemütlicher sind die Schiffahrten auf dem Bosporus nach Üsküdar und durch das goldene Horn.

Der Blick gegen die Altstadt mit all ihren Minaretten und Moscheen regte mich zu einem weiteren Bild an. Die nahe Dolmabahçe Moschee und die grosse Autobahnbrücke über den Bosporus zeigen weitere Eindrücke der zwischen West und Ost geteilten Stadt.
Im Zentrum der Altstadt aquarellierte ich die wunderbare Sultan Ahmed Moschee und konnte trotz allem Abwehren nicht verhindern, dass der kleine Schuhputzer, der sich lange aufdrängte, endlich dezidiert meinen Schuh packte, mit Schuhwichse bestrich und so lange daran herumpolierte, bis mein Schuhwerk glänzte wie noch nie vorher.

Als ich dann etwas weiterwanderte und eben im Begriffe war, die Hagia Sophia zu skizzieren, wurde ich von einem sehr aufdringlichen, gut angezogenen jungen Mann angesprochen, der mir nur ganz schnell seine Werkstatt zeigen wollte. "Du brichst mir mein Herz" rief er aus, nachdem ich ihm höflich, aber bestimmt sagte, ich möchte jetzt in aller Ruhe malen. Um so besser ist mir der nette, uniformierte Torwächter eines Amtes ganz in der Nähe meines Standorts in Erinnerung, der mich hinter den Zaun zog, mir einen antiken Säulenstumpf als Sitzplatz anbot und dann voller Interesse zuschaute, wie ich malte und mir dabei mit seinen Fingern auch ab und zu sachkundige Verbesserungsvorschläge gab.

Ein besonderes Erlebnis wurde die Kariye Camii, eine mit byzantinischen Fresken reich geschmückte Kirche, nicht nur wegen ihrer Bilder, sondern auch wegen des interessanten Hinweges. In einem Tram, das vom Topkapipalast zur Stadtmauer führt, fragte ich nach dem Weg, worauf zwischen mehreren Passagieren eine Diskussion begann, die darin gipfelte, dass eine Frau mich beim Aussteigen mitnahm, über mehrere Strassen zu einem Sammeltaxi führte, mit dem Fahrer diskutierte, wo er mich aussteigen lassen solle, was denn auch getreulich ausgeführt wurde und erst noch $\mathrm{zu}$ einem erstaunlich billigen Fahrpreis. Nach der Kirche zeigte mir ein Taxifahrer dann die Stadtmauer mit den besten Orten zum Fotografieren und empfahl mir noch einen Ausflug in das nahegelegene Eyüp, benannt nach dem Fahnenträger des Propheten Ayyub al-Ansarî. Das Grab dieses Mannes ist heute noch immer ein stark besuchter Pilgerort. Der grosse, verkehrsfreie Platz vor der Moschee wimmelt von Tauben und Menschen in orientalischen Gewändern und war für mich von erstaunlicher Erlebnisdichte.

Voller bleibender Eindrücke von Sonnenuntergängen und Silhouetten von Moscheen und Minaretten reiste ich zurück in die Schweiz, die gesamthaft viel weniger Einwohner hat als die eindrückliche Stadt Istanbul allein. 